\title{
ENFERMERÍA Y DOCTORADO
}

En la anterior editorial recordábamos que el Real Decreto 1393/2007, de 29 de 0ctubre, por el que estableció la ordenación de las enseñanzas universitarias, organizaba los estudios oficiales universitarios en Grado, Máster y Doctorado (art 3, punto 1). Con esta nueva estructura, a todas las carreras universitarias (Grados) se les reconocía el acceso al segundo ciclo (Máster) y posteriormente al Doctorado. Como norma general, para acceder a los estudios de Doctorado, el estudiante tiene que reunir 300 créditos ECTS (240 del Grado y 60 de un Máster). También reconocía otras posibilidades de acceso al Doctorado, en número de créditos, para las titulaciones universitarias actuales (Diplomaturas y Licenciaturas).

Recientemente se ha publicado el RD 99/2011, de 28 de enero, por el que se regulan las enseñanzas oficiales de doctorado. Este RD viene a regular el desarrollo del tercer ciclo dentro de la construcción del Espacio Europeo de Educación Superior (EEES), así como la construcción del Espacio Europeo de Investigación (EEI). De esta forma, se define con claridad la misión de los doctores en la nueva sociedad del conocimiento, lo que redundará en el reconocimiento profesional y prestigio social, la idoneidad en las perspectivas laborales y en sus aportaciones al nuevo modelo de crecimiento.

En su preámbulo destaca, que la formación de investigadores es, en estos momentos, un elemento clave de una sociedad basada en el conocimiento. El reconocimiento social de las capacidades adquiridas en esta etapa formativa, la necesidad de incrementar sustancialmente el número de personas con competencia en investigación e innovación y el impulso a su influencia y empleo tanto dentro como fuera de los ámbitos académicos es uno de los principales desafíos españoles y europeos.

Como aspectos fundamentales del RD podríamos destacar que:

- Define el doctorado como el tercer ciclo de estudios universitarios oficiales, conducente a la adquisición de las competencias y habilidades relacionadas con la investigación científica de calidad.

- Los estudios de doctorado se organizarán a través de programas, en la forma que determinen los estatutos de las universidades y de acuerdo con los criterios establecidos en el presente real decreto. Dichos estudios finalizarán en todo caso con la elaboración y defensa de una tesis doctoral que incorpore resultados originales de investigación.

- La duración de los estudios de doctorado será de un máximo de tres años, a tiempo completo, a contar desde la admisión del doctorando al programa hasta la presentación de la tesis doctoral (cinco años a tiempo parcial).

Asimismo enumera las competencias que debe adquirir el doctorando:

a) Comprensión sistemática de un campo de estudio y dominio de las habilidades y métodos de investigación relacionados con dicho campo. 
b) Capacidad de concebir, diseñar o crear, poner en práctica y adoptar un proceso sustancial de investigación o creación.

c) Capacidad para contribuir a la ampliación de las fronteras del conocimiento a través de una investigación original.

d) Capacidad de realizar un análisis crítico y de evaluación y síntesis de ideas nuevas y complejas.

e) Capacidad de comunicación con la comunidad académica y científica y con la sociedad en general acerca de sus ámbitos de conocimiento en los modos e idiomas de uso habitual en su comunidad científica internacional.

f) Capacidad de fomentar, en contextos académicos y profesionales, el avance científico, tecnológico, social, artístico o cultural dentro de una sociedad basada en el conocimiento.

Finalmente enumera los requisitos de acceso al doctorado, que con carácter general y como comentaba al principio, será necesario estar en posesión de los títulos oficiales españoles de Grado, o equivalente, y de Máster Universitario. Como novedad, reconoce también la posibilidad de acceso a los titulados universitarios que, previa obtención de plaza en formación en la correspondiente prueba de acceso a plazas de formación sanitaria especializada, hayan superado con evaluación positiva al menos dos años de formación de un programa para la obtención del título oficial de alguna de las especialidades en Ciencias de la Salud.

\section{Referencias}

- Real Decreto 1393/2007, de 29 de octubre, por el que se establece la ordenación de las enseñanzas universitarias oficiales.

- Real Decreto 861/2010, de 2 de julio.

- Real Decreto 861/2010, de 2 de julio, por el que se modifica el Real Decreto 1393/2007, de 29 de octubre, por el que se establece la ordenación de las enseñanzas universitarias oficiales.

- Real Decreto 99/2011, de 28 de enero, por el que se regulan las enseñanzas oficiales de doctorado.

Rodolfo Crespo 